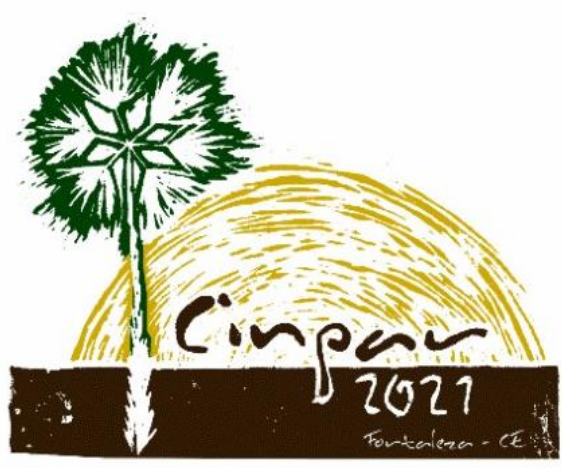

XVII Congresso Internacional sobre Patologia e Reabilitação das Construções

XVII Congreso Internacional sobre Patología y Rehabilitación de las Construcciones

XVII International Conference on Pathology and Constructions Rehabilitation

FORTALEZA (Brasil), 3 a 5 de junho de 2021 https://doi.org/10.4322/CINPAR.2021.093

\title{
Proposta e Aplicação de Lista de Verificação para Manutenção Predial com Base no Método GUT: Estudo de Caso em Rio Branco, Acre
}

\section{Proposal and Application of Checklist for Building Maintenance Based on GUT: Case Study in Rio Branco, Acre}

\author{
Nalbhert Albuquerque VIANA ${ }^{\mathbf{1}}$, Arquiney Augusto Rodrigues MAIA ${ }^{2}$, Antonia Alana LIMA PACHECO $^{3}$ \\ ${ }^{1}$ Centro Universitário UNINORTE, Rio Branco - AC, Brasil, nalbhert@gmail.com \\ ${ }^{2}$ Centro Universitário UNINORTE, Rio Branco - AC, Brasil, aarquiney@gmail.com \\ ${ }^{3}$ Escola Politécnica da Universidade de São Paulo, São Paulo - SP, Brasil, alanapacheco@usp.br
}

\begin{abstract}
Resumo: Na formulação do plano de manutenção predial, a identificação das manifestações patológicas é fundamental na determinação de qual fenômeno deve ser priorizado para reparo. O objetivo do presente trabalho é propor uma lista de verificação (checklist) baseada no método GUT que auxilie a manutenção predial e avalie de forma quantitativa a prioridade de recuperação dos problemas encontrados em alvenaria, piso e cobertura através da inspeção predial. Para isso, o checklist foi elaborado com base nas áreas de inspeção, manifestações patológicas visíveis e índice de criticidade, e teve o intuito de obter parâmetros que determinassem qual dano patológico possuía mais urgência em manutenção. A lista foi aplicada em um estudo de caso e verificou-se que a infiltração e o desplacamento do piso cerâmico foram os problemas mais críticos identificados na edificação. Por fim, o checklist conseguiu definir os problemas com mais urgência em manutenção e mostrou-se de fácil compreensão, com elementos intuitivos que permitiram rápida aplicação.
\end{abstract}

Palavras-chave: Checklist. Manutenção predial. Manifestação patológica.

Abstract: In the development of a previous building maintenance plan, identifying pathological manifestations is essential to determine what problem should be prioritized in repair. The purpose of this paper is to propose a checklist based on the GUT method that assists the building maintenance and quantitatively evaluates the recovering priority of recovering the problems found in masonry, floor and roof through building inspection. The checklist was prepared based on the inspection areas, visual pathological manifestations and criticality index. It was intended to obtain parameters that would determine which pathological damage had the most urgency in maintenance. The list was applied in a case study, and it was found that the infiltration and the detachment of the ceramic floor tiles were the most critical problems identified in the building. Finally, the checklist was easy to understand, with intuitive elements that allow quick application, and it was able to define the pathological problems with more urgency in maintenance.

Keywords: Checklist. Building Maintenance. Pathological manifestation.

\section{Introdução}

Qualquer empreendimento na construção civil está diretamente relacionado com a necessidade do usuário em utilizá-lo, logo a entrega do produto deve estar de acordo as exigências técnicas para que atenda ao cliente com a qualidade esperada. Além disso, torna-se de fundamental importância a conservação das construções existentes, a fim de diminuir-se os gastos com novas edificações. Partindo dessa necessidade, a inspeção predial aliada à manutenção predial, objetivam garantir a durabilidade e a segurança de uma 
edificação, onde por meio de checklist, da determinação de prioridades e da classificação de risco, é possível elaborar um plano de manutenção corretiva que progredirá para a manutenção preventiva (IBAPE-PR, 2016). Essa manutenção possui um custo significativo na fase de uso da edificação e não deve ser feita de modo improvisado. Ela é um serviço técnico, que necessariamente deve ser programada como forma de investimento na preservação do valor patrimonial (ABNT, 2012).

No entanto, é notável a falta de uma norma regulamentadora que vise padronizar métodos e orientar os inspetores prediais, a fim de definir as prioridades em manutenção. Devido a tal ausência, instituições e associações de profissionais da área desenvolvem materiais próprios que atendam a sua atual necessidade (Böes, 2017).

A matriz GUT desenvolvida por Kepner e Tregoe (1981) surge então como uma metodologia quantitativa para a definição das prioridades na solução de problemas. Ela considera a Gravidade (G), a Urgência (U) e a Tendência $(T)$ dos problemas encontrados como parâmetros de verificação para determinação de uma nota que defina o grau de criticidade em relação a cada problema encontrado. Esse método foi adaptado por Verzola et al. (2014) de forma a possuir aplicabilidade na área de inspeção predial, como ferramenta para classificação dos riscos. É o caso do trabalho de Böes (2017) que correlaciona a gravidade GUT com a criticidade do Método CMB (Crítico, Médio e Baixo) para definir o grau de risco do dano patológico, além de propor modelos de checklists e questionários. De forma semelhante, Braga et al. (2019) aplica a metodologia supracitada na avaliação de manifestações em prédios históricos e ressalta que a aplicação da matriz GUT exige conhecimento e experiência na área de patologias da construção, apesar de se mostrar de grande utilidade por não ser uma técnica invasiva.

Sendo assim, o artigo tem como objetivo propor uma lista de verificação (checklist) com base no método GUT para auxiliar a manutenção predial, avaliando de forma quantitativa a prioridade de recuperação de fenômenos patológicos e aplicá-la em um estudo de caso para verificação da sua eficiência. $O$ trabalho está delimitado à inspeção visual detalhada nas área de revestimento, piso e cobertura de um edifício comercial. Dessa forma, almeja-se contribuir para o fomento de pesquisas na área de inspeção e manutenção predial através do desenvolvimento e aplicação de métodos sistêmicos que objetivem a agilidade e economia na tomada de decisões.

\section{Metodologia}

A primeira etapa do trabalho consistiu na formulação de uma lista de verificação (checklist) para manutenção predial baseada no método GUT, tomando como modelo a proposta de lista de verificação para inspeção predial desenvolvida por Verzola et al. (2014). O foco do checklist foi tomado a partir das solicitações de reparo que eram emitidas à Coordenadoria de Manutenção Predial do Campus Rio Branco, na Universidade Federal do Acre (UFAC). Dessa forma, as áreas de revestimentos, coberturas, pisos e forros foram a base para construção do trabalho referido. $O$ modelo do checklist está apresentado no Apêndice A deste trabalho.

Na segunda etapa foi realizada a aplicação do checklist modificado em visita técnica ao bloco de medicina veterinária da UFAC, inaugurado em 2017, no município de Rio Branco-AC (Figura 1). O prédio de dois pavimentos, construído em estrutura de concreto armado, com fechamento lateral em alvenaria convencional, abriga os programas de pós-graduação e bacharelado em Medicina Veterinária. 0 edifício foi escolhido devido à ocorrência de problemas incomuns em seu interior, considerando seu pouco tempo de utilização. O levantamento de dados foi feito com auxílio da lista de verificação e registros fotográficos, a partir dos quais foi possível formular um mapa dos danos encontrados na área interna da edificação.

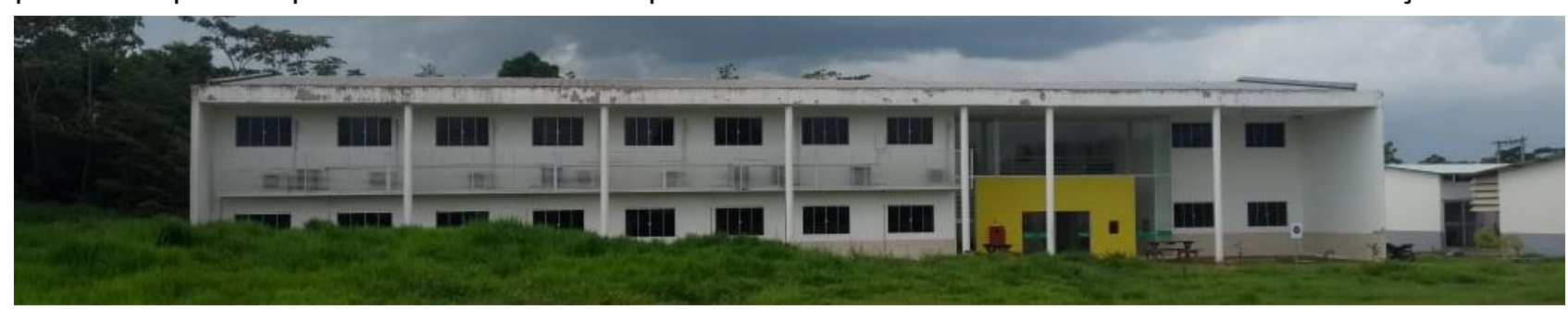

Figura 1 - Bloco de Pós-Graduação em Medicina Veterinária 


\section{Proposta de Lista de Verificação}

O Quadro 1 apresenta a classificação GUT onde são atribuídas notas de 1 a 10, sendo o maior número, a classificação mais grave. Com todas as notas determinadas, se calcula o produto $(G) \times(U) \times(T)$ e o resultado dessa multiplicação, resulta na nota final que define a prioridade do dano analisado (Braga et al., 2019).

Quadro 1 - Classificação GUT quanto a Gravidade (G), Urgência (U) e Tendência (T) (Verzola et al., 2014, modificado)

\begin{tabular}{|c|c|c|c|}
\hline & GRAU & DEFINIÇÃO DO GRAU & NOTA \\
\hline \multirow{5}{*}{ 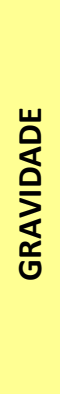 } & TOTAL & $\begin{array}{l}\text { Risco de morte, impacto irrecuperável, perda excessiva de desempenho, prejuízo } \\
\text { financeiro muito alto. }\end{array}$ & 10 \\
\hline & ALTA & Perigo de lesão aos usuários, danos recuperáveis ao meio ambiente e à edificação. & 8 \\
\hline & MÉDIA & Risco à saúde dos usuários avarias ao meio ambiente reversíveis, perda financeira média. & 6 \\
\hline & BAIXA & $\begin{array}{l}\text { Sem risco de saúde, baixa degradação ao meio ambiente, necessidade de substituição de } \\
\text { alguns sistemas, perda financeira baixa. }\end{array}$ & 3 \\
\hline & NENHUMA & Sem risco de saúde, mínima deterioração do ambiente, nenhum dano de valor. & 1 \\
\hline \multirow{5}{*}{ 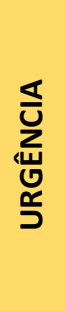 } & TOTAL & Acontecimento imediato, necessidade de interdição do imóvel sem prazos extras. & 10 \\
\hline & ALTA & Acontecimento na iminência de acontecer, urgente intervenção. & 8 \\
\hline & MÉDIA & Adversidade prevista para breve, necessidade de intervir rapidamente. & 6 \\
\hline & BAIXA & Inicialização de um incidente, intervenção ainda em forma de planos. & 3 \\
\hline & NENHUMA & Adversidade imprevista, mas necessário acompanhamento para futuras manutenções. & 1 \\
\hline \multirow{5}{*}{ 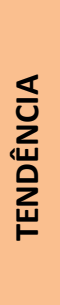 } & TOTAL & Progresso da manifestação imediato, podendo haver pioras a qualquer instante. & 10 \\
\hline & ALTA & Evolução da situação prestes a ocorrer. & 8 \\
\hline & MÉDIA & Evolução a médio prazo. & 6 \\
\hline & BAIXA & Possível evolução a longo prazo. Poderá vir a ocorrer. Situação de demora. & 3 \\
\hline & NENHUMA & Situação estabilizada, sem evolução do caso. & 1 \\
\hline
\end{tabular}

Um recorte da lista de verificação desenvolvida neste trabalho está apresentado no Apêndice A - Checklist proposto. O checklist completo aplicado ao longo do trabalho e no estudo de caso se dividiu em:

a) Características Físicas: refere-se à disposição construtiva da edificação, ao obter dados de área construída, número de ambientes e altura do pé direito.

b) Revestimentos (fachadas): descreve-se o tipo de revestimento utilizado nas fachadas da edificação.

c) Revestimentos (paredes internas): neste item demarca-se o tipo e quantitativos de revestimento utilizado nas paredes de cada ambiente da edificação.

d) Pisos: assinala-se o tipo de revestimento utilizado no piso de cada ambiente da edificação. Em caso de revestimento misto, é necessário indicar área coberta por ele. Já em caso de troca ou demolição, mensura-se em porcentagem da quantidade necessária.

e) Cobertura: este item subdivide-se em três tipos (cobertura, calhas e rufos), onde determinamse o tipo e as dimensões de cada elemento utilizado na cobertura da edificação. Em caso de troca ou demolição, mensura-se em porcentagem a quantidade necessária.

f) Forros: este item subdivide-se em dois tipos (forro interno e externo), onde determina-se o material utilizado no forro e suas respectivas áreas e o tipo de estrutura para fixação. Em caso de troca ou demolição de algum elemento, mensura-se em porcentagem a quantidade necessária. 
Na seção "manifestações patológicas visíveis", estão listadas os problemas mais comuns relacionadas a cada sistema, assinalando "SIM" para a existência e "NÃO" para ausência. Os fenômenos que compõem a lista de verificação proposta, com suas respectivas localizações são:

- Revestimentos (fachadas e paredes internas): Rachaduras, infiltração, desplacamento cerâmico, deterioração das juntas e descascamento da pintura;

- Pisos: Rachaduras, infiltração, desplacamento cerâmico, deterioração das juntas e afundamento de piso;

- Cobertura: Ferrugem, apodrecimento da madeira, telhas quebradas, destelhamento parcial, destelhamento total, quebra parcial ou total (calhas e rufos), entupimento (calhas e rufos), estanqueidade (calhas) e desplacamento (rufos);

- Forros: Rachaduras, infiltração, manchas, apodrecimento de madeira/cupim, ferrugem, desplacamento.

Por fim, a subseção "índice de criticidade" é composta por Gravidade (G), Urgência (U) e Tendência (T), onde as notas são atribuídas conforme exposto no Quadro 1 . Em seguida, multiplica-se as notas anteriores obtendo-se a pontuação final que determina o "grau de prioridade" em executar o reparo, este grau é determinado conforme Quadro 2. Além disso, para melhor localização dos ambientes e suas manifestações patológicas, foram anexados à lista proposta, a planta baixa e as vistas da edificação.

Quadro 2-Grau de prioridade

\begin{tabular}{|c|c|}
\hline Pontuação & Grau de Prioridade \\
\hline $1-99$ & NENHUMA \\
\hline $100-299$ & BAIXA \\
\hline $300-599$ & MÉDIA \\
\hline $600-799$ & ALTA \\
\hline $800-1000$ & TOTAL \\
\hline
\end{tabular}

Fonte: Autor

Como instrumento de auxílio na identificação de manifestações patológicas visíveis, o checklist proposto é modificável conforme seja a edificação em estudo, mas para isso, deve-se conhecer a metodologia GUT que está descrita no rodapé da lista de verificação e explicada detalhadamente no corpo deste trabalho. Para definição dos itens recomenda-se realizar visita prévia ao local de aplicação e assim obter informações que os projetos podem não fornecer.

\section{Estudo de Caso}

Após configuração final do checklist adaptado para o edifício, realizou-se visita técnica com o objetivo de aplicar efetivamente a lista proposta. A Figura 2 apresenta fotos das manifestações patológicas encontradas na fachada norte do prédio, como a infiltração e o descascamento da pintura; classificadas com grau de prioridade médio por interferirem apenas no aspecto visual, mas que tendem a evoluir caso não haja intervenção. Seguindo estes passos, a lista foi preenchida conforme mostra a Figura 3, atribuindo uma nota para cada manifestação patológica encontrada.

De forma similar, a Figura 4 exibe fotografias do desplacamento cerâmico ocorrido no piso do pavimento superior do edifício, que ocorreu em diversos ambientes daquele local, representados conforme legenda. A partir de análise visual do problema, é possível supor que o destacamento do piso cerâmico está relacionado com a excessiva deformação da laje sobre a qual se assenta, podendo então a peça trabalhar como uma capa de compressão da laje, ocasionando o que pode ser visto ao longo de todo o pavimento. O checklist foi preenchido conforme mostra a Figura 5, atribuindo notas que resultaram em um grau de prioridade total, devido ao problema estar interferindo na utilização da edificação e por poder vir a causar lesão aos seus usuários, por conta do alto fluxo de transeuntes nessa área. 


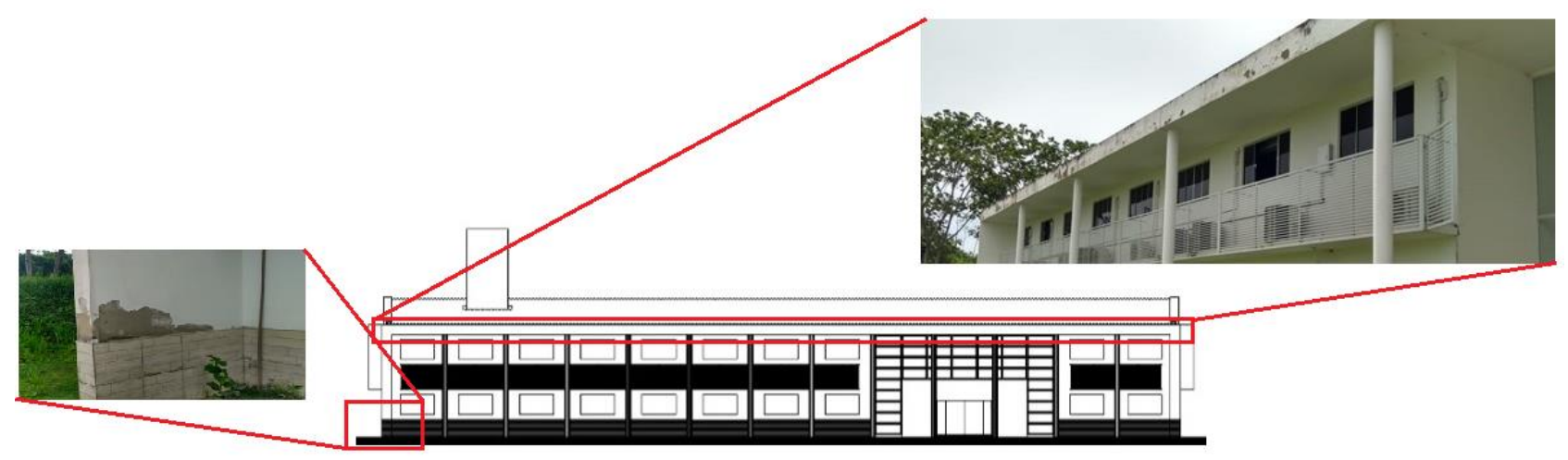

Figura 2 - Infiltração e descascamento da pintura na fachada norte

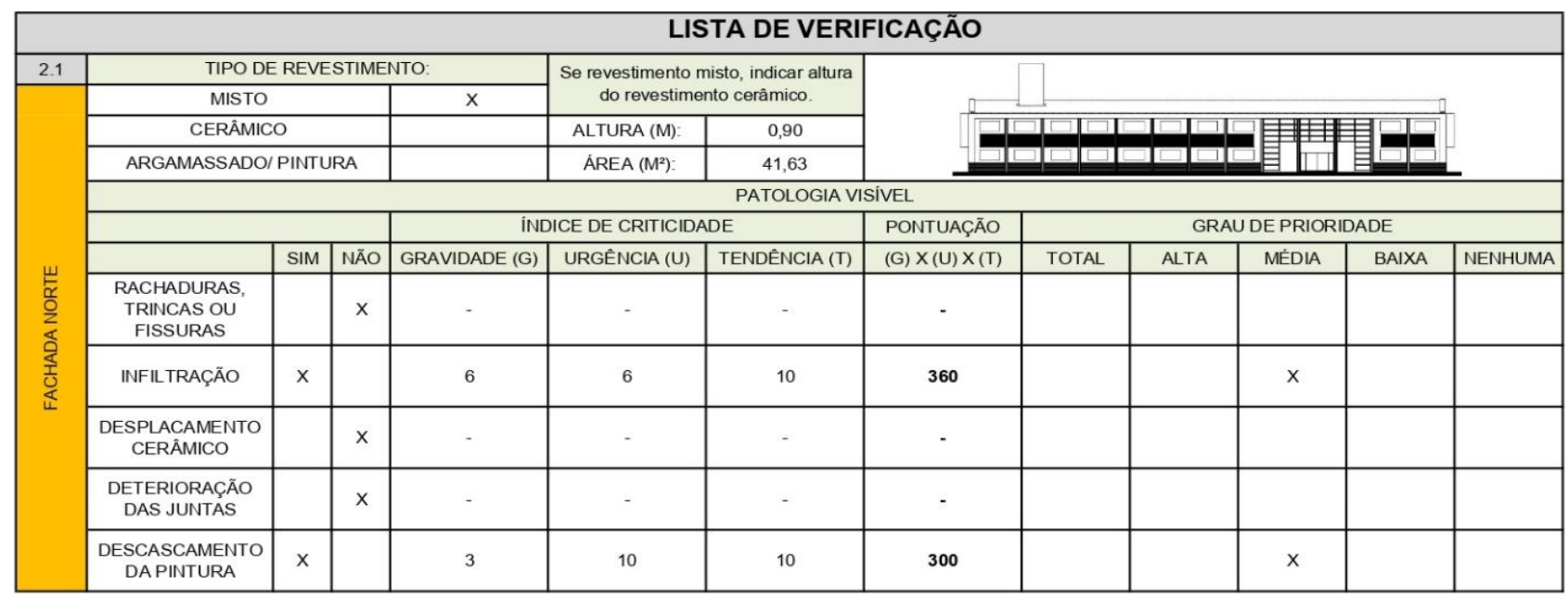

Figura 3 - Checklist da fachada norte preenchido

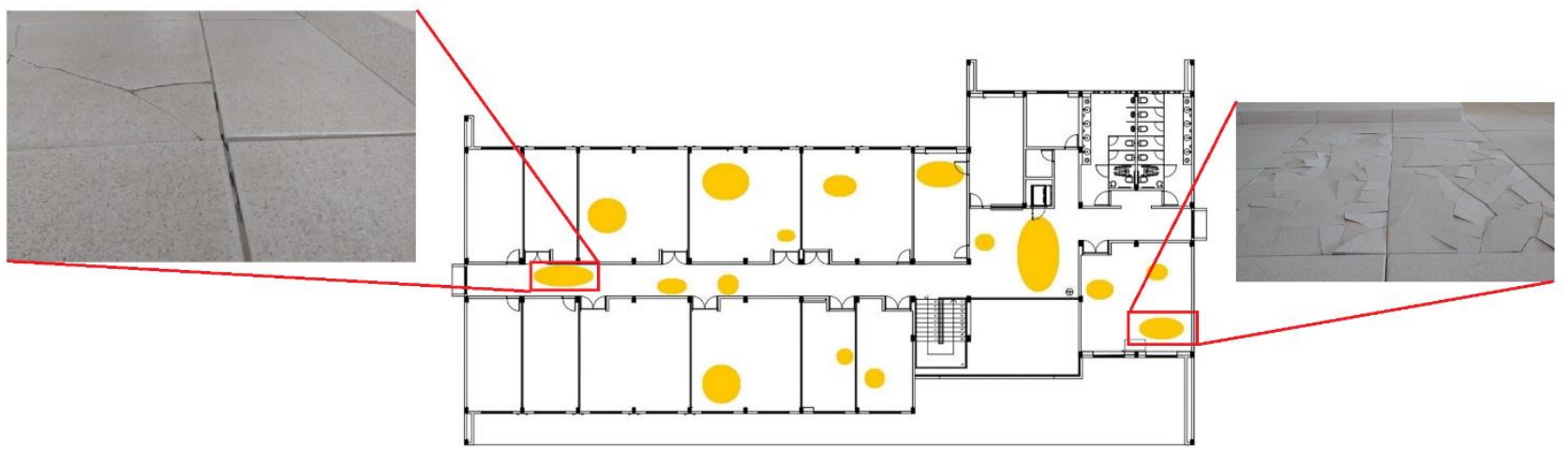

DESPLACAMENTO CERÂMICO

Figura 4 - Pavimento superior com desplacamento cerâmico do piso

O mesmo procedimento foi repetido para as outras fachadas do edifício, as paredes internas do pavimento térreo, o forro e a cobertura. Com o preenchimento do checklist, foi possível mensurar quantitativamente as anomalias existentes nos sistemas da edificação em estudo e através do método GUT aplicado pela lista de verificação proposta, verificou-se que a infiltração nos revestimentos de paredes e fachadas, é uma das manifestações patológicas que apresentam prioridade em recuperação e que a mesma pode ser o fator causal do descascamento da pintura. A Figura 6 apresenta o mapa dos problemas de infiltração encontradas no térreo, onde as paredes representadas na cor azul indicam a sua presença. 


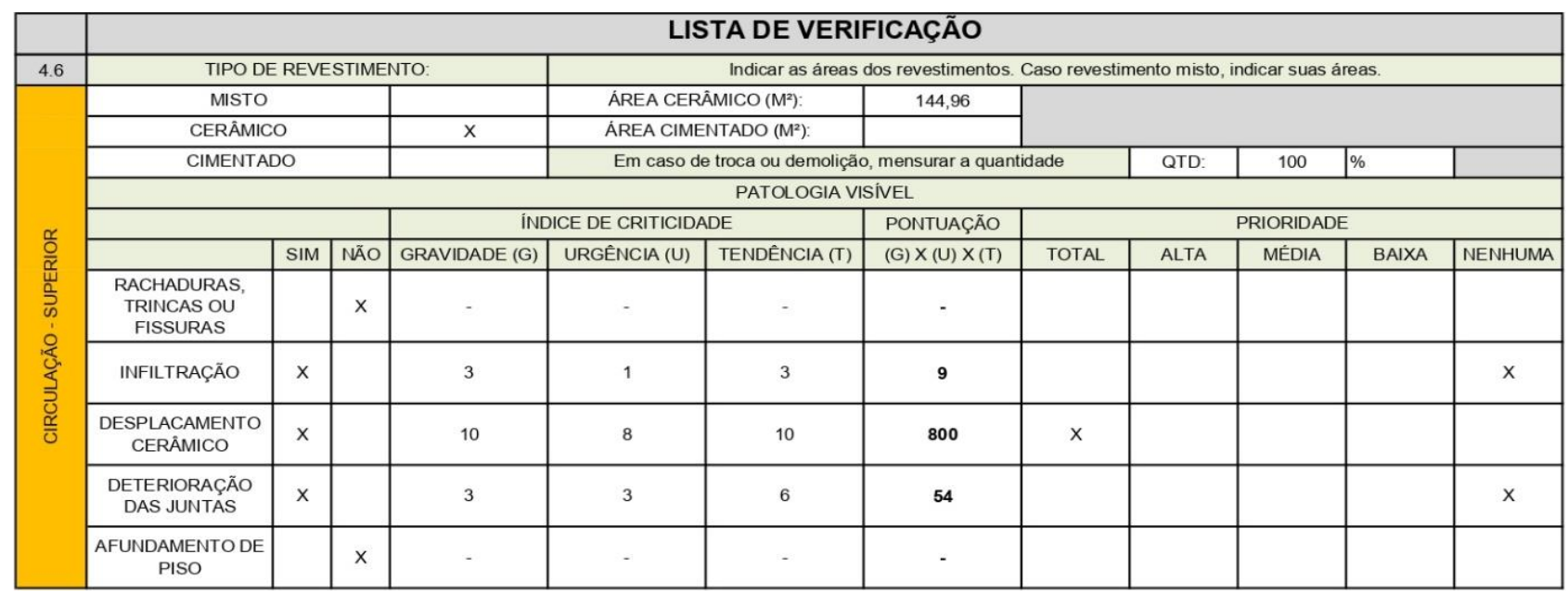

Figura 5 - Checklist da área de circulação no pavimento superior

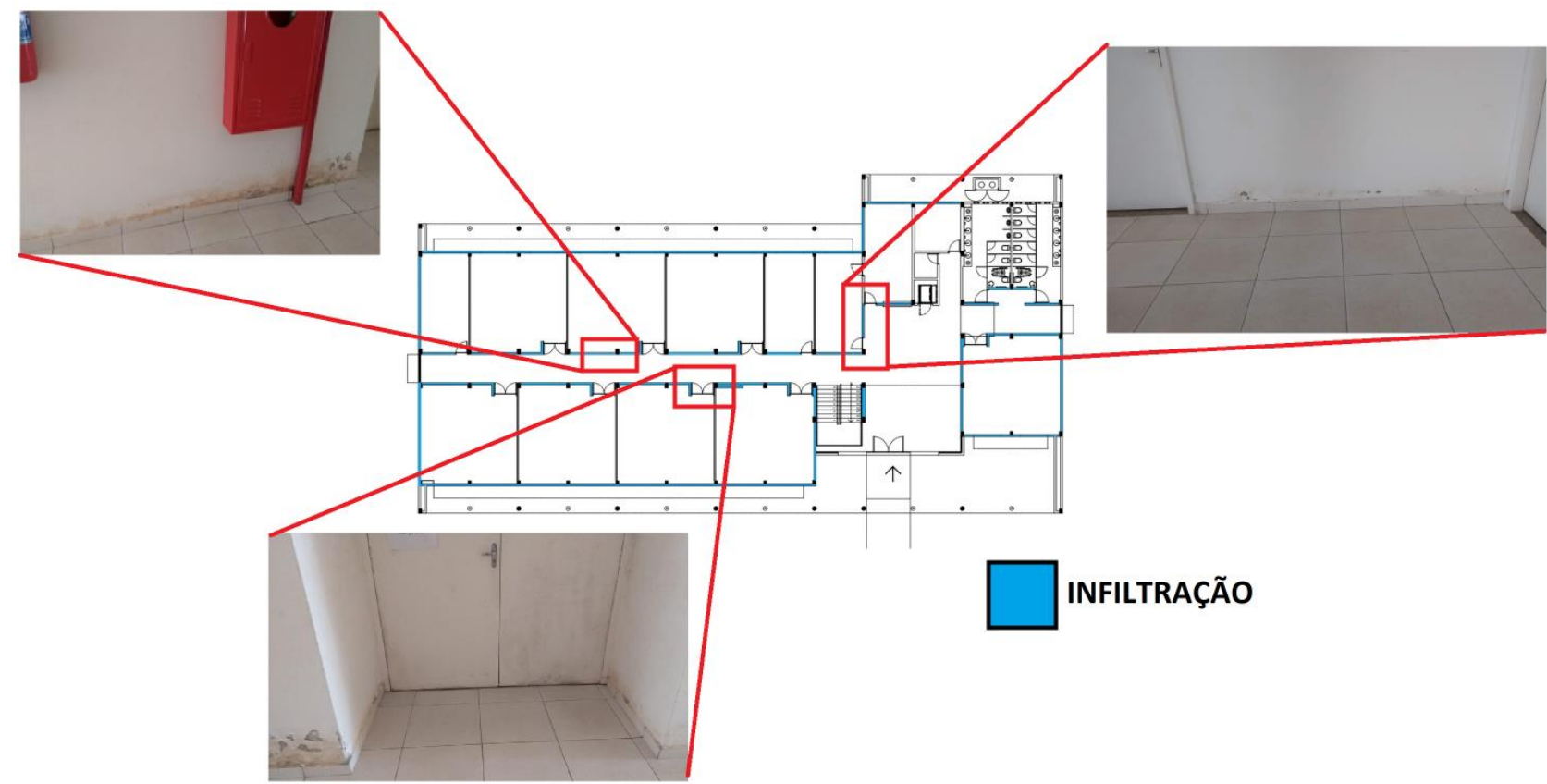

Figura 6 - Pavimento térreo com infiltração em paredes

Por fim, a Figura 7 apresenta um gráfico resumo com as manifestações patológicas que obtiveram maior grau de prioridade em manutenção, determinadas através do checklist pelo método GUT. É importante ressaltar que as pontuações representadas no eixo horizontal são o somatório de cada manifestação patológica ao longo de todos os ambientes analisados do prédio. Por exemplo, cada ambiente interno (banheiros, laboratórios, circulação, etc.) que apresentou descascamento da pintura se atribuiu 144 pontos, somando pontuação total de 720 .

A análise mostra que o desplacamento cerâmico do pavimento superior obteve maior pontuação, devido aos fatores de abrangência e danos aos usuários. Entretanto, a infiltração está presente em mais sistemas da edificação (revestimentos, forros e cobertura), permitindo que ocasione outros danos que assim estão representadas no gráfico e que possuem sua parcela de significância, como é o caso do desplacamento do forro de gesso e o descascamento da pintura nas paredes.

A partir da prioridade em manutenção definida, a Universidade realizou a manutenção corretiva no bloco. Foram substituídas as placas cerâmicas com largura maior nas juntas de assentamento de todos os ambientes atingidos, também como a retirada e substituição do emassamento existente das paredes internas e assentamento de revestimento cerâmico na altura de $1 \mathrm{~m}$. Desta forma, a lista de verificação proposta pelo presente trabalho, mostrou-se eficaz na prática, sendo ferramenta que contribuiu para a formalização de 
dados, descrevendo detalhes dos ambientes e caracterizando os problemas encontrados de acordo com seu o grau de prioridade em manutenção.

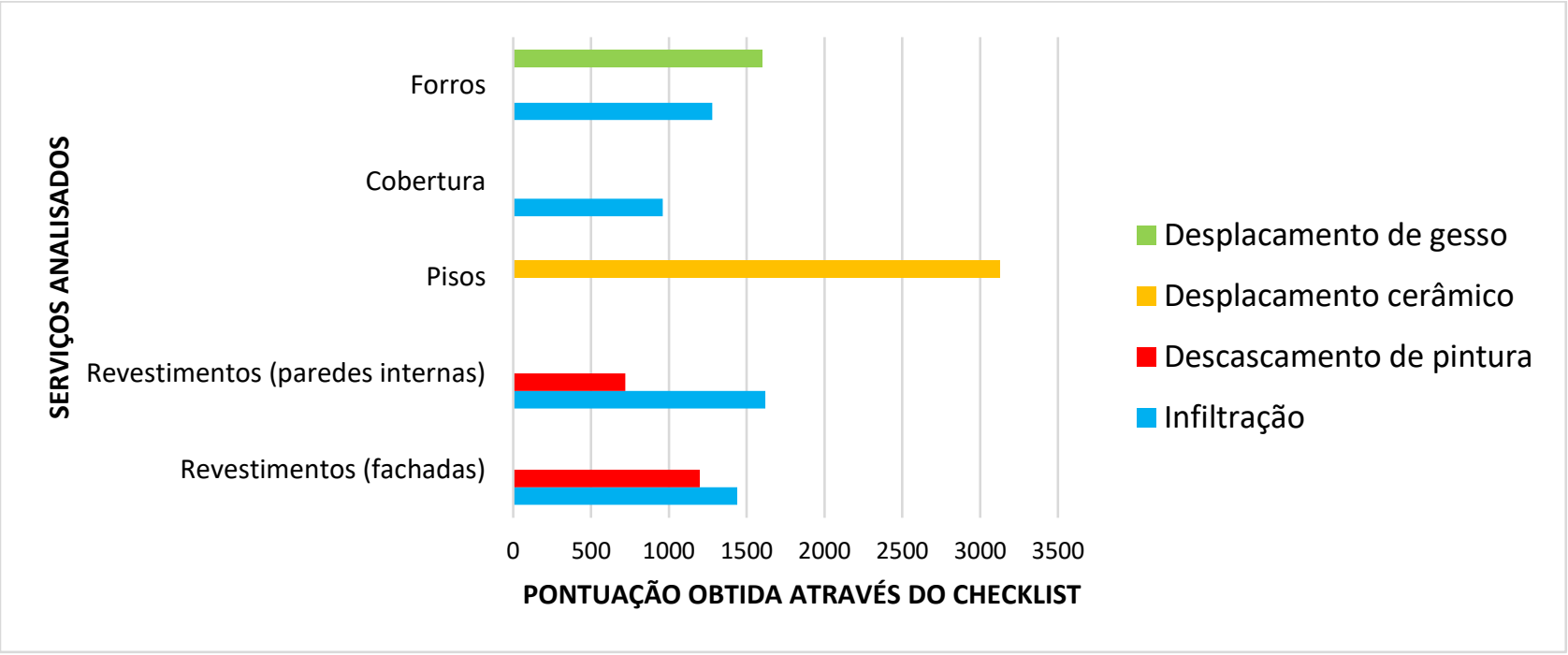

Figura 7 - Manifestações patológicas com maior grau de prioridade em manutenção determinadas pelo método GUT

\section{Conclusões}

O checklist proposto com base no método GUT permitiu avaliar a prioridade em reparo das manifestações patológicas encontradas e funcionou como um formulário para as constatações técnicas das anomalias encontradas, facilitando o levantamento de dados em campo e tornando a vistoria mais dinâmica.

O desplacamento cerâmico foi o dano que obteve em um só sistema, o maior grau de prioridade. Seguido pela infiltração que foi encontrada em três sistemas distintos do edifício, obtendo pontuação de média para alta em prioridade de manutenção. Estes dados foram determinantes na formulação do plano de intervenção que viria a ser feito no bloco.

De toda forma, acredita-se que este trabalho venha a fomentar a discussão no que se refere ao controle das manutenções prediais em edifícios públicos, quantificando os problemas mais recorrentes e urgentes, de modo que, o custo de reparo venha diminuir ao longo do acompanhamento destas edificações.

\section{Agradecimentos}

Os autores agradecem ao Centro Universitário UNINORTE, onde o trabalho foi inicialmente desenvolvido. Antonia A. L. Pacheco agradece ao CNPq (bolsa número 140054/2020-0).

\section{Referências Bibliográficas}

ABNT, ASSOCIAÇÃO BRASILEIRA DE NORMAS TÉCNICAS. NBR 5674 - Manutenção de edificações - Requisitos para o sistema de gestão de manutenção. Rio de Janeiro. 2012.

BÖES, J. S. Inspeção Predial: uma metodologia integradora para identificação e priorização de manifestações patológicas em edificações In: XIII Congresso Internacional sobre Patologia e Reabilitação de Estruturas. Crato. 2017

BRAGA, I. C. Aplicação da Matriz GUT na análise de manifestações patológicas em construções históricas. Revista ALCONPAT, Progreso, v. 09, n. 03, p. 320-335, set./dez. 2019.

IBAPE-PR - Instituto Brasileiro de Avaliações e Pericias de Engenharia do Paraná. Inspeção e Manutenção Predial. Paraná: IBAPE-PR, 2016.

KEPNER, C. H.; TREGOE, Benjamin B. O administrador racional. São Paulo: Atlas, 1981

VERZOLA, S. N.; MARCHIORI, F. F.; ARAGON, J. O. Proposta de Lista de Verificação para Inspeção Predial X Urgência das Manutenções In: XV Encontro Nacional de tecnologia do ambiente construído, Maceió, 2014. 


\section{Apêndice A - Checklist Prosposto (Demonstrativo)}

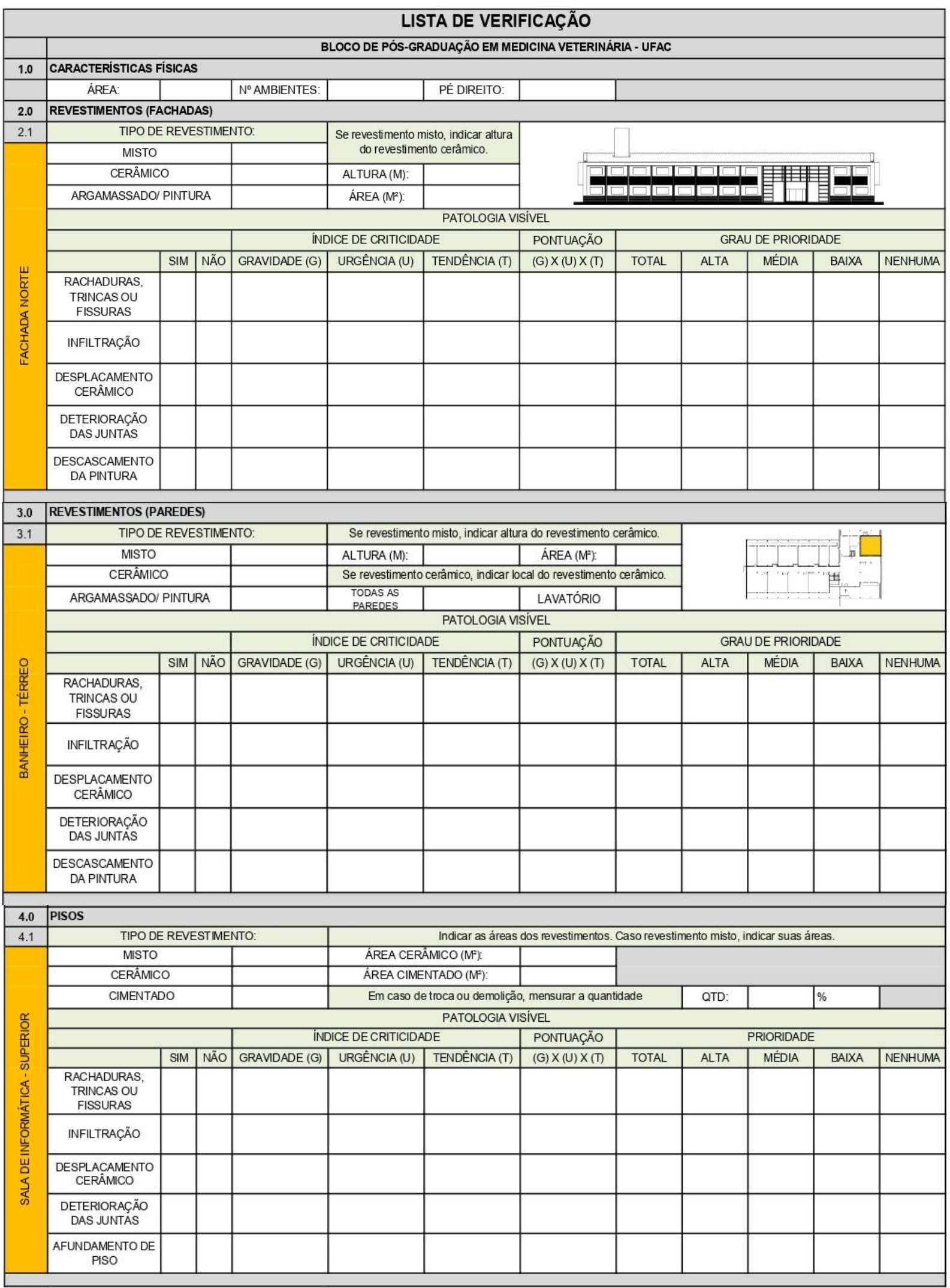

